\title{
Priming the pump: Does providing information before a crisis communications simulation provide a better learning experience?
}

\author{
Matthew Tidwell \\ University of Kansas \\ Lawrence, Kansas USA
}

\begin{abstract}
Many crisis communications educators use simulations as a means for students to test their learning in a controlled environment meant to simulate a real-life crisis using an (often hypothetical) organization. This project explores whether providing background and historical information about the organization days or weeks in advance of the simulation can enhance learning. Survey results of students exposed to this method as well as a traditional scenario approach (where all information is provided at once) showed that students preferred the advanced exposure method. The learning experience was judged to be superior overall. In addition, the recognition of understanding risks as well as improvements in teamwork were also noted.
\end{abstract}

Keywords - Simulation, Organizational Communication, Crisis Communication

SUGGESTED CITATION: Tidwell, M. (2019). Priming the pump: Does providing information before a crisis communications simulation provide a better learning experience? Proceedings of the International Crisis and Risk Communication Conference, Volume 2 (pp. 31-34). Orlando Fl: Nicholson School of Communication and Media. https://doi.org/10.30658/icrcc.2019.9

\section{INTRODUCTION}

The use of simulations in crisis communication instruction is common. By presenting students with hypothetical crisis scenarios, instructors will often test students' knowledge of message and response strategy, teamwork, interaction with media, etc. This practicum usually takes the form of full-scale, role-playing simulations where students take on the role of various communications or operational staff, or can be implemented using simple, table-top style discussion.

Traditionally, students receive all the information about the simulation they will take part in when they arrive for the simulation class session. They receive an explanation of the organization as well as the crisis that has just impacted the organization. This pilot project tested whether providing the organizational background information a few days or weeks in advance of the simulation would allow for a better learning experience.

\section{LITERATURE REVIEW}

SIMULATIONS AS A LEARNING TOOL

Simulations have long been recognized as an effective way to promote active learning. The hypothetical scenarios that serve as the basis for simulations can increase crisis readiness and provide important "performance tests" [3]. Scholastic researchers have discussed simulations' value as active learning tools. Active learning is seen as a motivator for student success but also as a tool to allow students to become better critical thinkers through making their own decisions rather than following the lead of others [4]. By practicing important skills like key message development and media interaction, students test their knowledge and abilities in a dynamic, yet controlled, environment. If correctly executed, simulations are also thought to improve teamwork skills. 
THE IMPORTANCE OF UNDERSTANDING RISKS AND PRODROMES

Realizing the importance of a comprehensive review of risks and working to determine possible impact on an organization's operations and reputation are important learning objectives. Coombs \& Holladay [1] explain that risks need to be clearly known so crisis communicators can assess possible reputational damage. In his essay on best practices in crisis communications, Seeger [5] explains that "all organizations should identify the potential hazards they face".

In her crisis communications textbook, Fearn-Banks [2] advises learners to understand what she calls "prodromes" or precursor warning signs of potential crises. She suggests a "crisis inventory" that charts potential risks and prodromes based on their likelihood to occur and potential damage. Simulations should play a role in risk identification. Kleiboer [3] posits that crises scenarios can aid in preparedness by illuminating risks and threats in the controlled simulation environment.

\section{RESEARCH QUESTIONS AND PROCEDURES}

This project looked at two methods for introducing a hypothetical scenario in a classroom-based crisis communications simulation. The first method ("Method I" for the purposes of this project) is a traditional model where the students are introduced to the organization and the crisis simultaneously as the simulation begins. The second method ("Method II") introduces background and historical information about the hypothetical organization days or weeks before the simulation commences. Having executed both methods in my career as a crisis communications instructor, I am interested about possible advantages and better learning outcomes accruing through the second method.

Specific research questions asked 1] whether Method II allows for better appreciation for the identification of risks and prodromes in crisis communications planning activities and 2] if Method II fosters more robust teamwork as students must work together earlier to review prodromes and forecast risk prior to beginning the simulation exercise.

Graduate students $(\mathrm{n}=15)$ in a recent crisis communications course participated in a voluntary survey after the course. Participants were asked their opinions about both methods I and II (as they had experienced both during in-class exercises) measured on a scale ranging from $1=$ definitely agree to $5=$ definitely disagree. Surveys were administered and results were tabulated and reported via Qualtrics.

\section{RESULTS}

I wanted to explore broad, overall reaction to the comparison in methods first. Students were first asked which method provided the better overall learning experience. Results showed broad agreement that students viewed Method II as a better overall learning experience with $93 \%(M=1.9, S D=0.26)$ indicating they definitely agreed.

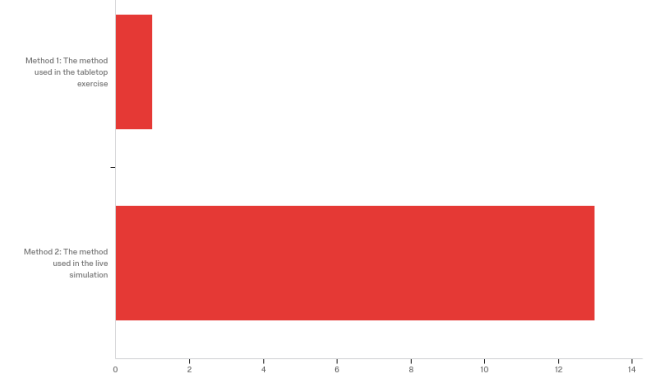

As to whether Method II allowed for better appreciation of the value of understanding risks and prodromes, $80 \%$ were either in somewhat or definite agreement while $20 \%(M=1.73, S D=1.34)$ indicated a level of disagreement. 


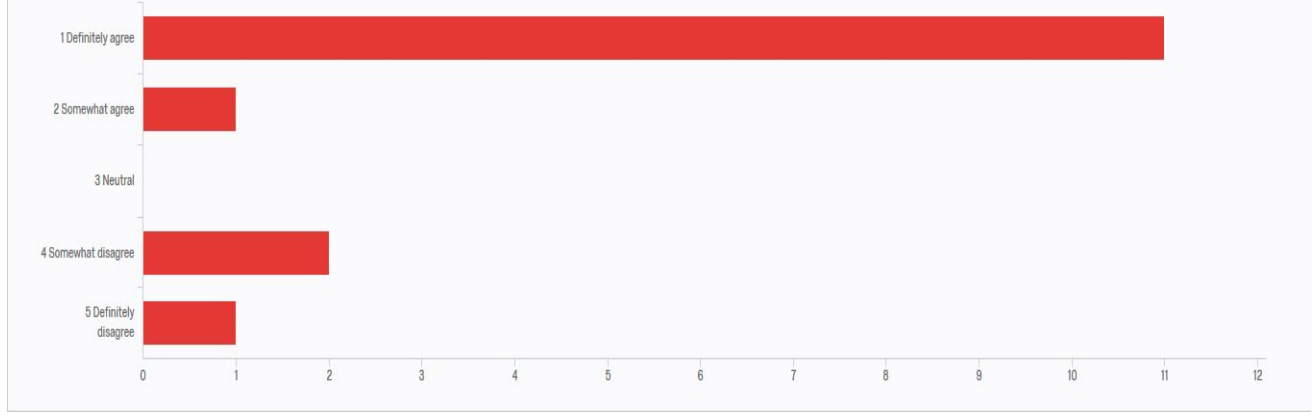

Results were slightly more mixed for the question about whether students agreed that the quality of teamwork was better in Method II. While the majority of the students (60\%) were in agreement, a substantial percentage was neutral (nearly $27 \%$ ) with the rest indicating a level of disagreement $(M=2.13, S D=1.26)$.

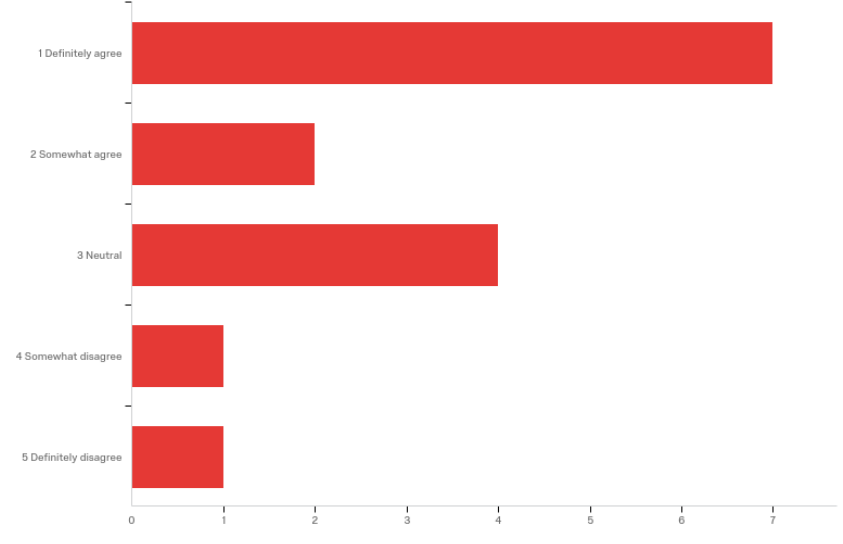

I encouraged open comments in order to obtain elaboration as to why the majority of students felt that Method II provided the superior learning experience. One respondent specifically referenced the additional time provided to think about the possible risks: "This method produced more thought because we knew a crisis was coming, but we had to think through many potential issues to prepare. Because of this, we had several issues on our mind that could arise from the actual crisis and I think this created a more thoughtful approach." Another student mentioned the improved realism: "The advantage of assimilating background prior to the simulation, plus the pressure to perform in real-time, concentrated the mind." A third student observed that having more detail about the organization earlier made for better results when preparing for the mock press conferences that were part of the simulation: "I believe that having as much background information as possible allows us to answer any reporter questions more effectively."

\section{DISCUSSION}

Much prior scholastic research exists looking at the value of simulations in teaching crisis communications. This real-time practice in a safe environment allows for students to see the value of concepts and theories discussed in the classroom. This pilot project sought to determine if the typical plan used in running classroom simulations could be enhanced by changing the methodology to introduce hypothetical information sooner than the day of the exercise. In addition, the project looked at whether this methodology could impact two important learning outcomes research tells us are necessary for effective crisis communications learning. Specifically, students should improve their skills in appreciating the need for risk identification as well as improving their teamwork skills.

This project had some limitations including a relatively small number of student respondents. Future research could utilize a larger set of students. Also, future researchers could look at manipulating variables including the level of detail provided and also perhaps lengthening the time between initial exposure to the details of the organization in the simulation and the simulation date. 


\section{CONCLUSION}

This project found broad agreement amongst students that providing details in advance made for a better learning experience on the day of the classroom crisis simulation. In addition, this method performed better in terms of students recognizing the critical need to gain an appreciation for advance risk identification in crisis communications planning and execution. While a majority of students reported that teamwork was improved using this method, the results in this area were more mixed.

\section{Author Biography}

Matthew Tidwell (mtidwell@ku.edu) earned his Ph.D. from the University of Kansas and teaches crisis communications in the university's graduate programs in integrated marketing communications and homeland security.

\section{REFERENCES}

[1] Coombs, W. T., \& Holladay, S. J. (2002). Helping crisis managers protect reputational assets: Initial tests of the situational crisis communication theory. Management Communication Quarterly, 16, 165-186. https://doi.org/10.1177/089331802237233

[2] Fearn-Banks, K. (2017). Crisis communications, a casebook approach. New York, NY: Routledge.

[3] Kleiboer, M. (1997). Simulation methodology for crisis management support. Journal of Contingencies and Crisis Management, 5(4), 198-206. https://doi.org/10.1111/1468-5973.00057

[4] Olson, K. S. (2012). Making It Real: Using a Collaborative Simulation to Teach Crisis Communications. Journal on Excellence in College Teaching, 2, 25-47. https://eric.ed.gov/?id=EJ972562

[5] Seeger, M. W. (2006). Best practices in crisis communication: An expert panel process. Journal of Applied Communication Research, 34, 232-244. https://doi.org/10.1080/00909880600769944 